\title{
Recognizing Black and Latinx Mathematical Excellence: The Blackwell-Tapia Prize
}

\section{Ron Buckmire}

Despite the many contributions mathematicians have made to the world, there are too few accolades to recognize excellence in mathematics. For example, there is no Nobel Prize in mathematics. The most prestigious prize for research in mathematics is widely considered to be the Fields Medal; it is presented to mathematicians under 40 years old at the quadrennial International Congress of Mathematicians. There have been 60 people who have won the Fields Medal and only two have been members of undrepresented groups (Maryam Mirzakhani and Artur Avila). For mathematicians who are active in mathematical research as well as interested in broadening the participation of underrepresented minorities in mathematics, the most prestigious award is the Blackwell-Tapia Prize. The Prize is awarded at the biennial Blackwell-Tapia Conference hosted by the National Science Foundation Mathematical Sciences Institutes. The conference and prize are named after David Blackwell and Richard Tapia.

Blackwell is one of the most celebrated African-American mathematicians of all time. He is the seventh Black person to receive a $\mathrm{PhD}$ in mathematics, which he did at the age of 22 in 1941. He was the first African American to be inducted into the National Academy of Sciences.

Ron Buckmire is Professor of Mathematics, Associate Dean for Curricular Affairs, and Director of the Core Program at Occidental College in Los Angeles, CA. He was a Program Officer in NSF's Division of Undergraduate Education from 2011 to 2013 and from 2016 to 2018. His email address is ron@oxy. edu.

Communicated by Notices Associate Editor Robin Wilson.

For permission to reprint this article, please contact: reprint - permission@ams .org.

DOI: https://dx.doi.org/10.1090/noti 1798
Blackwell was a full professor and head of the Mathematics Department at Howard University, which is a Historically Black College and University (HBCU). In 1954 he joined the faculty at the University of California at Berkeley (UCB) and became their first Black tenured professor. In 2018, UCB opened its newest residence hall, the David Blackwell Hall. Before Blackwell died in 2010, he made fundamental contributions to mathematical statistics, game theory, and information theory through his research, which led to notable results like the Rao-Blackwell theorem, Black-

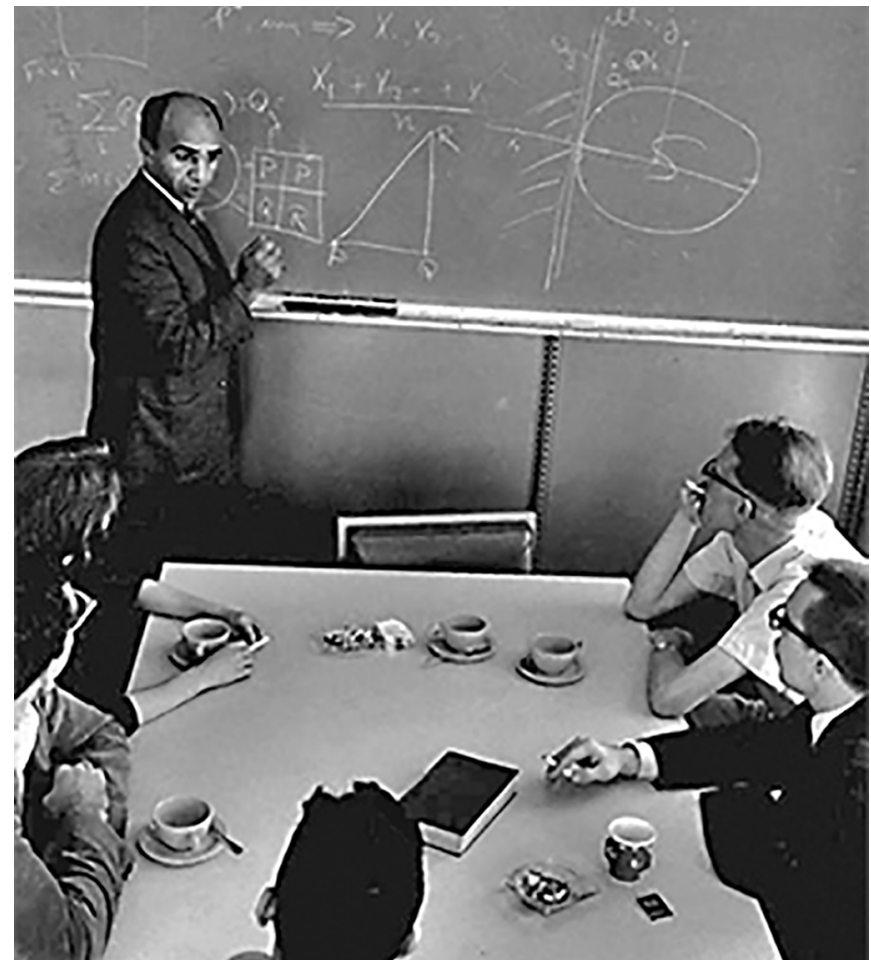

Figure 1. A young David Blackwell 
well's Approachability theorem, and Blackwell channels. Additionally, he wrote and published one of the very first textbooks on Bayesian statistics in 1969.

Richard Tapia is one of the most celebrated Latinx mathematicians in America. He is a longtime professor at Rice University in Houston, where among his many laurels he is a University Professor (one of six people ever designated with this title in the history of the institution). Tapia is also Maxfield-Oshman Professor of Engineering, and director of multiple initiatives to broaden the participation of underrepresented minorities in mathematics. He was awarded the National Medal of Science in 2011 by President Obama and in 1996 was appointed to the National Science Board by President Clinton. Tapia's mathematical research areas include scientific computing, specifically iterative methods for numerical solution of nonlinear problems, and various topics in mathematical optimization. Many know him for his work on integrating mathematics with drag racing. He is also the namesake for the Richard Tapia Celebration of Diversity in Computing conference.

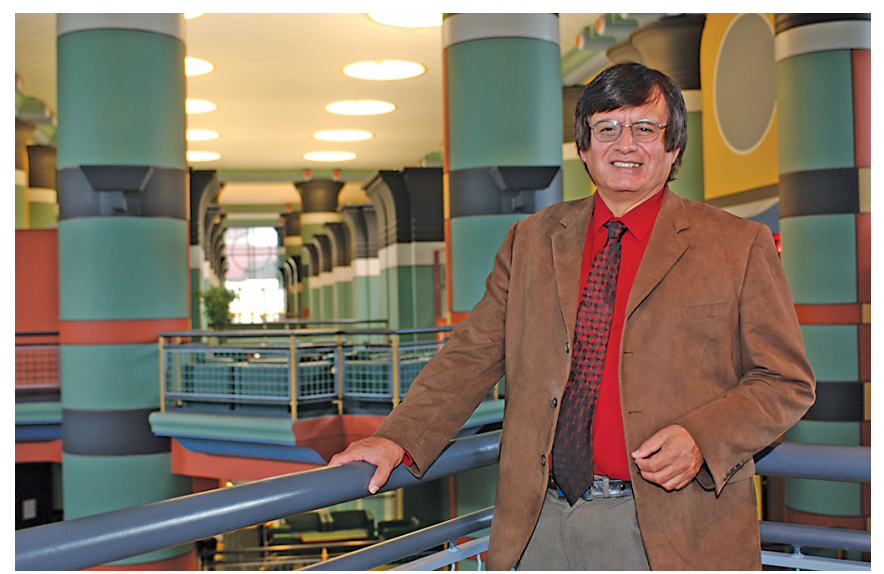

Figure 2. Richard Tapia

The Blackwell-Tapia Prize is awarded every two years to a mathematician who has a significant research portfolio and demonstrated interest and success in broadening the participation of underrepresented minority groups in mathematics. The prize has only been given nine times since 2002. The prize winners (in chronological order) are Arlie Petters (Duke University, 2002), Rodrigo Bañuelos (Purdue University, 2004), William S. Massey (Princeton University, 2006), Juan Meza (University of California, Merced and National Science Foundation, 2008), Trachette Jackson (University of Michigan, 2010), Ricardo Cortez (Tulane University, 2012), Jacqueline Hughes-Oliver (North Carolina State University, 2014), Mariel Vázquez (University of California, Davis, 2016) and Ronald E. Mickens (Clark Atlanta University, 2018).

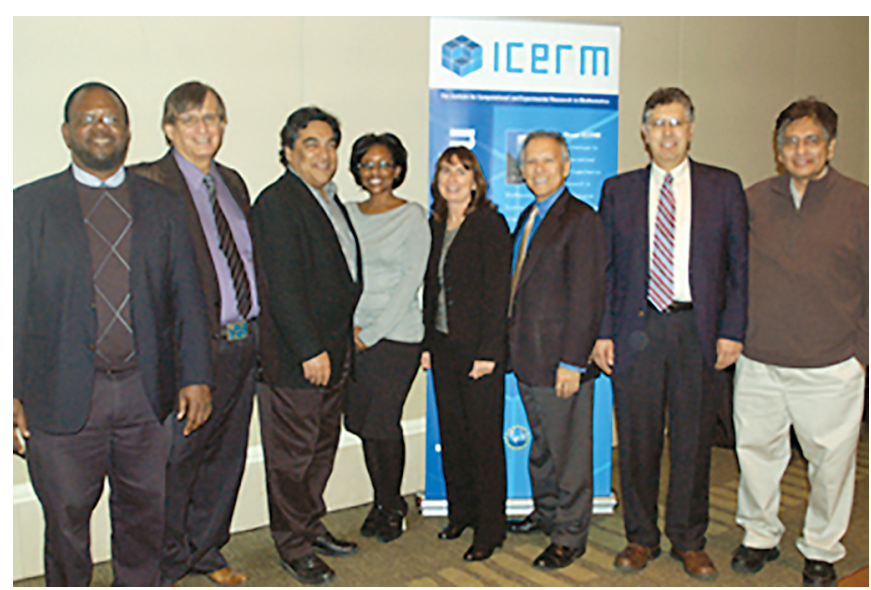

Figure 3. Five previous Blackwell-Tapia Prize winners: (From left to right) William Massey (2006), Richard Tapia, Ricardo Cortez (2012), Trachette Jackson (2010), Jill Pipher (founding director of ICERM), Juan Meza (2008), Rodrigo Banuelos (2004), and Carlos Castillo Chavez.

Mickens was announced to be the winner of the 2018 prize by the Blackwell-Tapia committee in April. The award was presented at the Tenth Blackwell-Tapia Conference held at the Institute for Computational and Experimental Research in Mathematics (ICERM) in November 2018. Mickens is the first person from an HBCU to win the Blackwell-Tapia Prize.

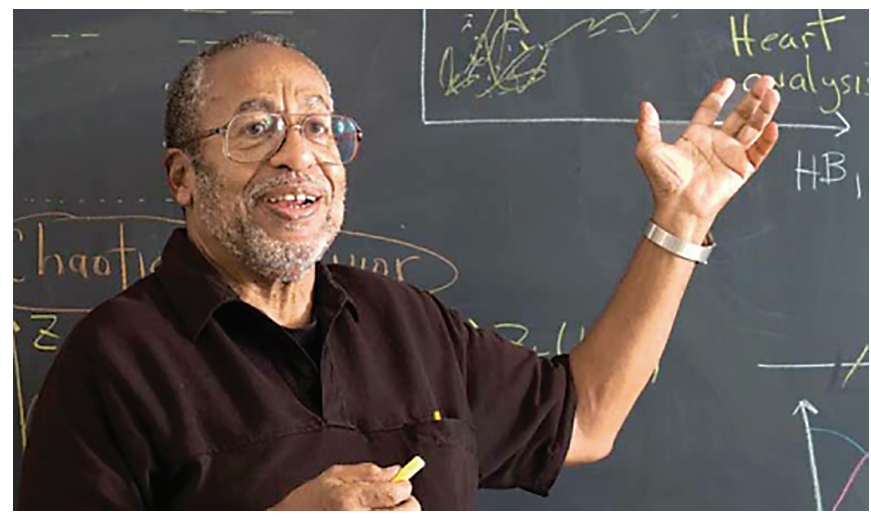

Figure 4. 2018 Blackwell-Tapia Prize winner Ronald E. Mickens.

Mickens is renowned for his voluminous and significant contributions to several areas of applied mathematics. Primarily he is known for his contributions to the analysis, approximation, and solution of differential equations, nonlinear oscillations, and difference equations. In particular, he developed and shaped the field of non-standard finite differences (NSFD) through his astonishing research productivity in this area, which is documented in eight books, more than 300 peer-reviewed publications, and countless talks and presentations. 


\section{COMMUNICATION}

In addition to his prodigious mathematical contributions, Mickens has a longstanding interest in the underrepresentation of people of African and Hispanic descent in mathematics and the other sciences. In 2002, he published the book Edward Bouchet: the First African American Doctorate and has regularly worked to excavate and publicize the accomplishments of many Black scientists. In addition to being a Ford Foundation Postdoctoral Fellow himself in 1980, Mickens has long mentored subsequent Ford Fellows, in many disciplines. As a faculty member at an HBCU, Mickens has served as a role model to thousands of students who have been in his classes and as an unofficial advisor to dozens of professionals in the mathematical sciences who are from various groups that are underrepresented based on race, gender, ethnicity, and sexual orientation.

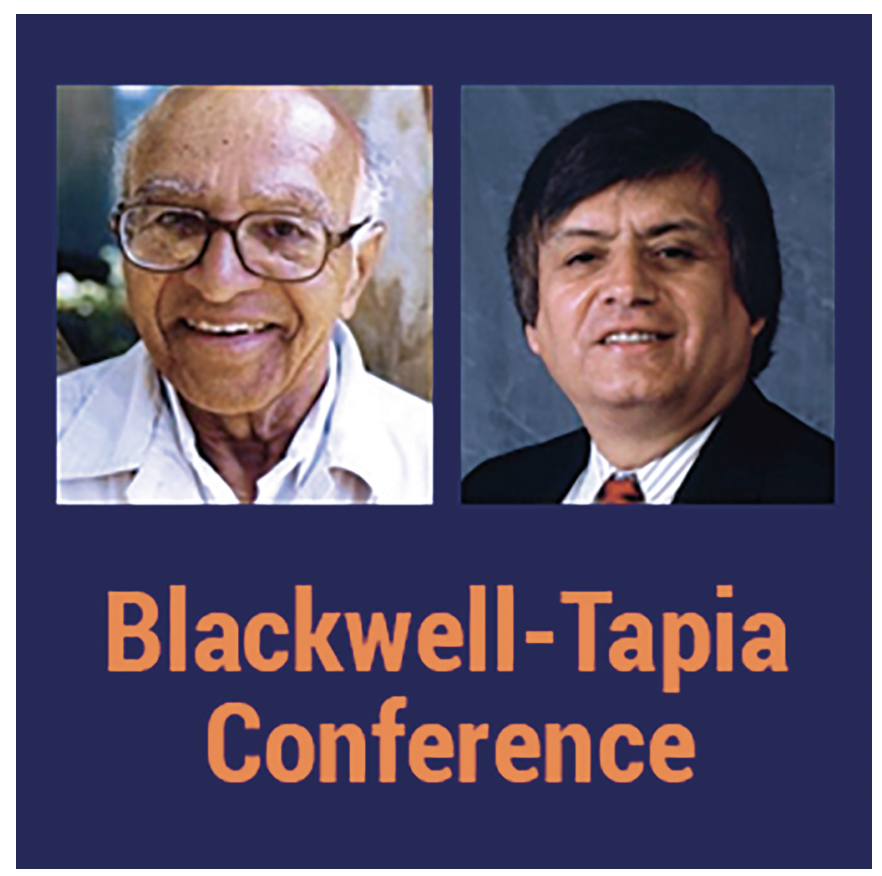

Mickens holds a PhD in Theoretical Physics from Vanderbilt University in 1968 and a Bachelor of Science in Physics from Fisk University in 1964. He is currently the Distinguished Fuller E. Callaway Professor in the Department of Physics at Clark Atlanta University, where he has been on the faculty since 1990. Before that, Mickens taught in the physics departments at Atlanta University (19821990) and Fisk University (1970-1982).

This author was one of several people who nominated Mickens for the Blackwell-Tapia Prize. The careers, the outlook, and the ambitions of people like myself and many others have been positively impacted by the example of excellence in mathematics that Dr. Ronald Mickens portrays to us all. 